\title{
Space charge dynamics in oil-impregnated pressboard under AC electric field
}

\author{
Miao $\mathrm{Hao}^{1}, \mathrm{Jiao}_{\mathrm{Hao}^{2}}$, Jin $\mathrm{Fu}^{2}$, Qian Wang ${ }^{2}$, Chao Tang ${ }^{3}$ and George Chen ${ }^{1}$ \\ ${ }^{1}$ Electronics and Computer Sciences \\ University of Southampton, UK \\ ${ }^{2}$ Chongqing Research Institute of the State Grid \\ Chongqing Electric Power Co, China \\ ${ }^{3}$ College of Engineering and Technology \\ Southwest University, China \\ mh2e10@soton.ac.uk
}

\begin{abstract}
Space charge has been a general concern related with the reliability and the life-time of HVDC components. In this present work, the space charge profiles in oil-impregnated pressboards are investigated by the means of the pulsed electroacoustic (PEA) technique under AC voltage with $50 \mathrm{~Hz}$ at the room temperature. It has been observed that the ageing status of the mineral oil and the presence of the oil gap can influence the charge accumulation significantly. In the fresh oil impregnated pressboard, considerable negative charges are accumulated near the aluminium electrode. However, only little or no space charge can be detected in the aged oil impregnated pressboard and the oil gap and pressboard composite insulation system. The results may suggest that the amount of the $\mathrm{AC}$ space charge is highly dependent on the charge mobility within the dielectrics. The higher charge mobility can result in a smaller amount of $\mathrm{AC}$ space charge.
\end{abstract}

Keywords-Space charge; PEA; HVAC; oil-paper; ageing.

\section{INTRODUCTION}

Oil pressboard insulation system has been widely applied in both conventional power transformers and converter transformers as the main insulation for a long time. It has been demonstrated that the presence of the space charge in the oil pressboard insulation under DC stresses can result in significant electric field distortion [1-3]. However, the space charge behaviour under $\mathrm{AC}$ stresses, especially with the power frequency, has been rarely investigated, due to the much smaller quantity of AC charge amount compared with DC one; and the requirement of the much faster data acquisition system in order to measure the phase related charge dynamics [4]. Some efforts has been made on the AC space charge in polymeric materials [5-9], which reveal that AC space charge is closely related to the frequency and the asymmetric properties of positive and negative charge carriers. In addition, little AC space charge has been observed in the multilayer oil impregnated Kraft papers [10]. However, the AC space charge behaviour and its influence factors in thick pressboards as well as in the oil gap and pressboard composite insulation system, which are generally applied in the transformers, are still poorly understood.

In this paper, the $\mathrm{AC}$ space charge dynamics in the two insulation systems: single layer pressboards, and oil gap composited with pressboard are investigated. The impacts of the degradation of the mineral oil are also involved in this work as comparison. Based on the previous works $[3,11]$, the aged oil pressboard, and the presence of the oil gap can be regarded as the enhancement of charge mobility. Therefore, the impacts of charge mobility on the AC space charge behaviour are discussed.

\section{EXPERIMENT}

\section{A. Sample preparation}

Two types of oil are used in this work, as a comparison, to investigate the impact of oil statuses on AC space charge dynamics, including the fresh oil and the service aged oil. The pressboards used in this work are $0.5 \mathrm{~mm}$ thick. The pressboards were cut into $10 \mathrm{~cm}$ in diameter to avoid flashover. The fresh oil was dried and degassed at $105 \square \mathrm{C}$ for 24 hours in vacuum. Similarly, the pressboards were dried at $105 \square \mathrm{C}$ for more than three days until the mass did not change. After that, the pressboards were immersed into the degassed fresh oil and aged oil separately under $60 \square \mathrm{C}$ in vacuum for three days to make sure the pressboards were fully impregnated with oil. Then, the samples were natural cooled to the room temperature. The fresh oil samples and the aged oil samples were kept in the vacuum condition to avoid to absorb the water from the environment. The dielectric statuses of the samples are shown in Table I.

TABLE I. DIELETRIC STATUSES OF THE SAMPLES

\begin{tabular}{|l|c|c|c|c|}
\hline & Fresh oil & $\begin{array}{c}\text { Fresh oil } \\
\text { impregnated } \\
\text { pressboard }\end{array}$ & Aged oil & $\begin{array}{c}\text { Aged oil } \\
\text { impregnated } \\
\text { pressboard }\end{array}$ \\
\hline $\begin{array}{l}\text { Resisivity } \\
(\mathrm{T} \Omega \mathrm{m})\end{array}$ & 7 & 140 & 0.1 & 0.3 \\
\hline Permittivity & 2.2 & 3.2 & 2.6 & 4.2 \\
\hline $\begin{array}{l}\text { Moisture } \\
(\mathrm{ppm})\end{array}$ & 5 & & 25 & \\
\hline $\begin{array}{l}\text { Breakdown } \\
(\mathrm{kV} / \mathrm{mm})\end{array}$ & 32 & & 21 & \\
\hline
\end{tabular}

\section{B. Experimental setup}

In order to capture the fast space charge dynamics under the AC voltage with a frequency of $50 \mathrm{~Hz}$, a faster data acquisition system is introduced to the PEA system, which consists of two essential component: a fast $\mathrm{HV}$ pulse generator $(2 \mathrm{kHz}, 1 \mathrm{kV})$ that allows to detect space charge under $\mathrm{AC}$ voltage with a frequency up to $100 \mathrm{~Hz}$; and a high performance 
digital signal averager 'Eclipse' which has a maximum sampling frequency of $2 \mathrm{GS} / \mathrm{s}$ with 8 -bit acquisition depth, and a large memory to record/store huge amount of space charge data. The whole experimental setup is illustrated in Fig.1. A low $\mathrm{AC}$ voltage is generated from the function generator (a superimposed voltage can also be generated from the function generator), which is then amplified 2000 times by the HV amplifier. This amplified high voltage AC voltage is applied to the top electrode of the purposed built PEA system used for the thick oil pressboard insulation system. Meanwhile, a series of high voltage pulse signals externally triggered by the Eclipse are applied on the top electrode, which make the charges in the sample to generate the acoustic signals. The acoustic signals are then transferred into electrical signals by the piezoelectric sensor. The PEA signals are acquired and stored by the Eclipse in a high sampling frequency. And then these raw data are sent to the computer for signal processing.

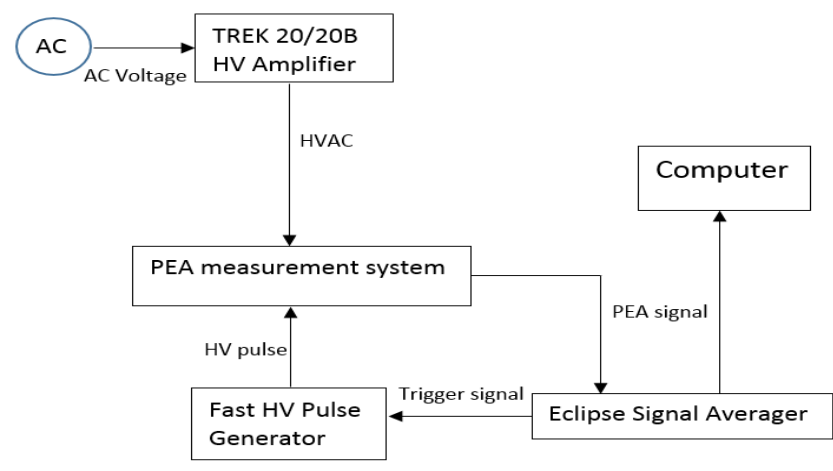

Fig. 1. Diagram of the AC space charge measurement system

There are two main steps for the signal processing, phase resolved PEA signal and calibration. The Eclipse can record 20 measurement points in a full $\mathrm{AC}$ cycle (including $50 \mathrm{~Hz} \mathrm{AC}$ voltage) with a fixed interval phase angle of $18^{\circ}$, and each measurement point is a data series of the space charge profile. The data acquisition is consecutively repeated for about 100 cycles of the AC voltage, by doing this, sufficient data can be used for averaging. As the sampling is not synchronized with the $\mathrm{AC}$ voltage, i.e. the start of the data acquisition is not synchronized with the zero-crossing point $\left(0^{\circ}\right.$ or $\left.180^{\circ}\right)$ of the $\mathrm{AC}$ voltage, the phase angle of the each measurement point in the $\mathrm{AC}$ voltage cycle has to be distinguished. Considering the capacitive charge on the electrodes is mainly determined by the applied voltage, it can be used to identify the phase angle of each measurement point. Technically, the capacitive charge, resulting from the amplitude of the external voltage, could be referred to the peak value of the charge density on the ground electrode (which suffers less from the severe acoustic attenuation) in each space charge profile. The procedures for distinguishing the phase angle of the PEA signal are briefly described as follows:

1. The data of the measurement points at a same phase angle within the 100 consecutive $\mathrm{AC}$ cycles are averaged to denoise. Therefore, 20 denoised signals can be obtained, which are distributed in a full $\mathrm{AC}$ cycle, and each signal is averaged about 100 times.

2. The peak value of the capacitive charge density on the ground electrode in each denoised signal is recorded and plotted in sequence. Then this plot is fitted with a Sine curve by Matlab, as shown in Fig.2. Therefore, the phase angle of each measurement point can be directly calculated by the fitted equation.

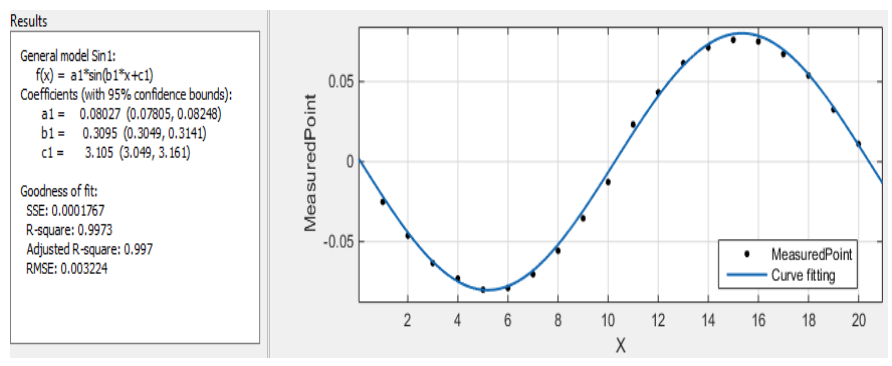

Fig. 2. Determination of the phase angle for each measurement point.

Once the phase angle of each measurement point is determined, the space charge results can then be calibrated by the reference data with a same phase angle by using the same calibration procedures in the DC measurements. By using this measurement system, the space charge profiles with 20 different phase angle can be recorded in each cycle. It is much more legible to compare all the space charge profile in the phase angle that is closed to $90^{\circ}$ or $270^{\circ}$. In this paper, the results at $81^{\circ}$ are picked as the example to show the time dependant $\mathrm{AC}$ space charge dynamics due to the limitation of the pages.

\section{Measurement protocol}

Considering the amount of the $\mathrm{AC}$ space charge could be very small, the volts-off measurements are applied to verify the space charge build up. As shown in Fig.3, volts-on measurement means the $\mathrm{AC}$ voltage is continuously applied during the data acquisition process. After each volts-on measurement, the applied external voltage is temporarily turned off. The residual space charge in the sample can be measured in a short period (about 30s for data acquisition and average 1024 time of the whole space charge profile along the sample by using the oscilloscope). The external voltage is then turned back on immediately after the completion of the voltsoff measurement. The external voltage is applied for 1 hour, and after that, the voltage is permanently removed, and the decay of the space charge is measured. All the measurements are completed at the room temperature. It has to be noticed that the volts-on results were measured by the Eclipse averager due to the fast alternating applied voltage and the volts-off results were obtained by the normal oscilloscope as the alternating voltage has been removed.

The applied AC electric field is $9.6 \mathrm{kV} / \mathrm{mm}$ in r.m.s.

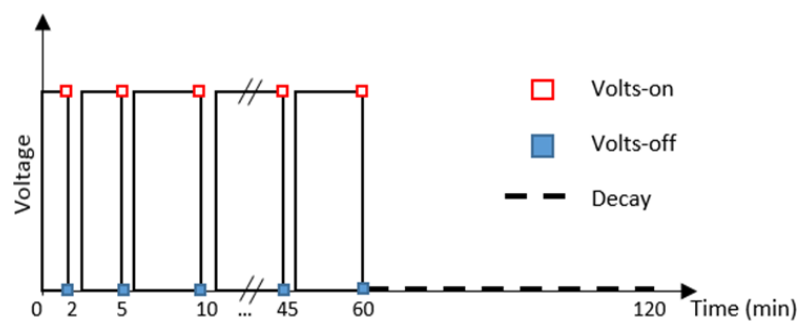

Fig. 3. Illustration of experiment measurement points. 


\section{RESULTS AND DISCUSSIONS}

\section{A. AC space charge in the single layer of fresh oil} impregnated pressboard

Fig.4 shows the space charge profiles at a phase angle of $81^{\circ}$ of the AC cycle during the 1 hour of the AC voltage application, in order to show the time dependent charge dynamics more clearly. It can be observed that a small amount of negative charges are injected from the ground electrode in to the pressboard in the vicinity of the ground electrode/pressboard interface. The accumulated AC space charge is also validated by the volts-off results, as shown in Fig.5. The negative charges are accumulated in the narrow vicinity of the interface between the ground electrode and the pressboard, which also induce a positive peak with a similar charge density on the ground electrode. The peak of the accumulated charges keeps increasing with AC voltage application and reaches to about $0.3 \mathrm{C} / \mathrm{m}^{3}$ during 1 hour. However, no accumulated charges can be observed in the vicinity of the top electrode, which may be due to the limited resolution of the PEA system at the top electrode side that is unable to distinguish the accumulated charges and the capacitive charges when they are distributed within a narrow area.

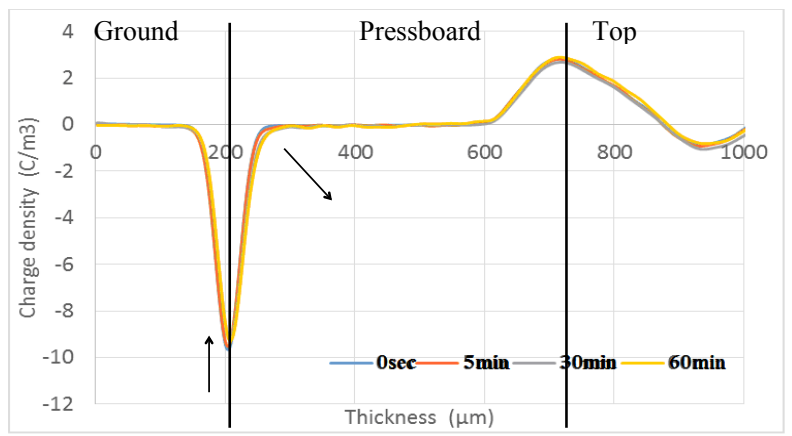

Fig. 4. Volts-on results of space charge in single layer fresh oil impregnated pressboard under $9.6 \mathrm{kV} / \mathrm{mm}$ AC field at $81^{\circ}$.

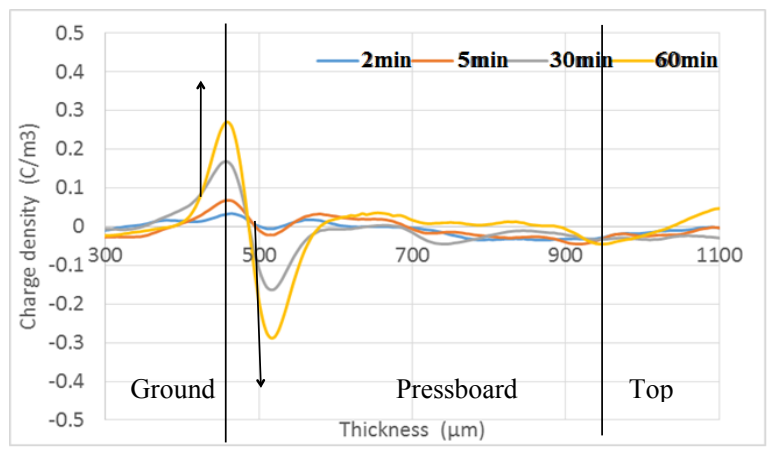

Fig. 5. Volts-off results of space charge in single layer fresh oil impregnated pressboard under $9.6 \mathrm{kV} / \mathrm{mm}$ AC field.

\section{B. Space charge in the single layer of aged oil impregnated pressboard}

Fig. 6 shows the space charge profiles at a phase angle of $81^{\circ}$ of the $\mathrm{AC}$ voltage with $50 \mathrm{~Hz}$ frequency in the aged oil impregnated pressboard. No obvious space charge accumulation can be observed, compared with the fresh oil impregnated pressboard. Only some small oscillations can be observed within the pressboard bulk. The volts-off results as a validation of the little accumulation of space charge are shown in Fig.7. A smaller negative charge peak (about $0.08 \mathrm{C} / \mathrm{m}^{3}$ ) can be observed, compared with the fresh oil sample. Moreover, the smaller positive charge peak (about $0.07 \mathrm{C} / \mathrm{m}^{3}$ ) can be observed at the $60 \mathrm{~min}$ within the pressboard bulk. This may suggest that the space charge within the aged oil sample may distribute in a much boarder area in the sample bulk due to the large mobility of the charges. These injected charges could be overlapped or recombined in the pressboard bulk that is difficult to be distinguished due to the limited spatial resolution of the PEA system, and only some oscillations can be detected.

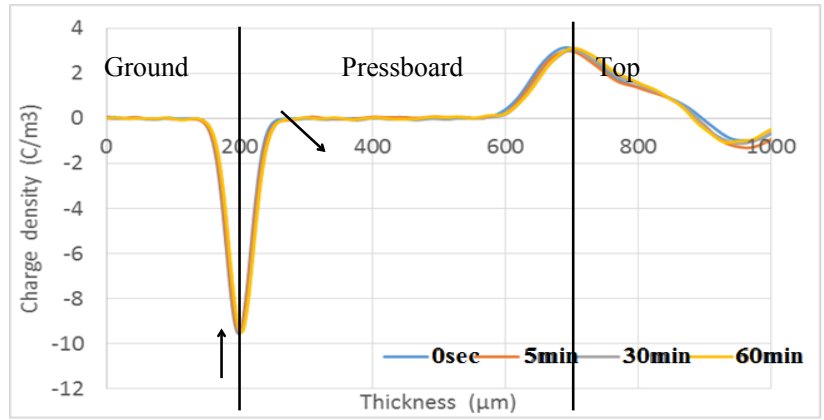

Fig. 6. Volts-on results of space charge in single layer aged oil impregnated pressboard under $9.6 \mathrm{kV} / \mathrm{mm}$ AC field at $81^{\circ}$

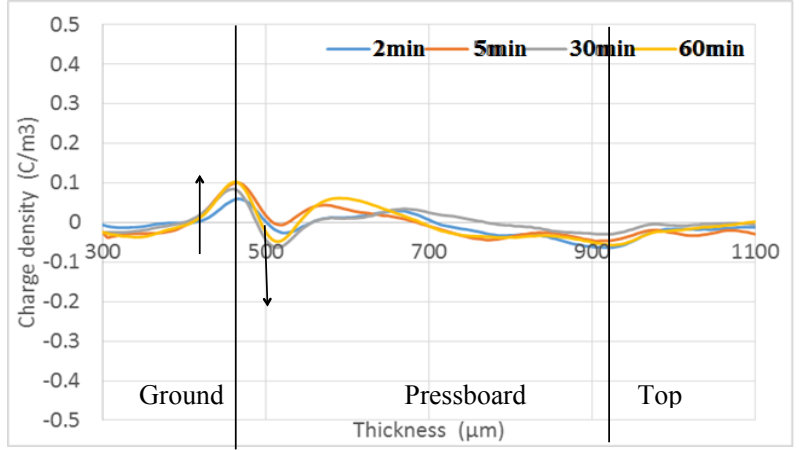

Fig. 7. Volts-off results of space charge in single layer aged oil impregnated pressboard under $9.6 \mathrm{kV} / \mathrm{mm}$ AC field.

\section{Space charge in the oil gap combined with a single layer impregnated pressboard}

When a fresh oil gap is applied between the fresh oil impregnated pressboard and the ground electrode, the space charge profiles at an $81^{\circ}$ phase angle of the $\mathrm{AC}$ voltage are shown in Fig.8. No accumulated space charge can be observed in the insulation system, only oscillations within the insulation bulk, which are also confirmed by the volts-off results, as shown in Fig.9 and Fig.10 (aged oil sample). The range of the oscillations are from $+0.03 \mathrm{C} / \mathrm{m}^{3}$ to $-0.03 \mathrm{C} / \mathrm{m}^{3}$, which is believed as the background noise.

The summary of the total charge amount in the different samples, as shown in Table II, clearly show that the largest amount of the AC space charge are in the single layer fresh oil pressboard which is regarded as the dielectric with the lowest charge mobility. 


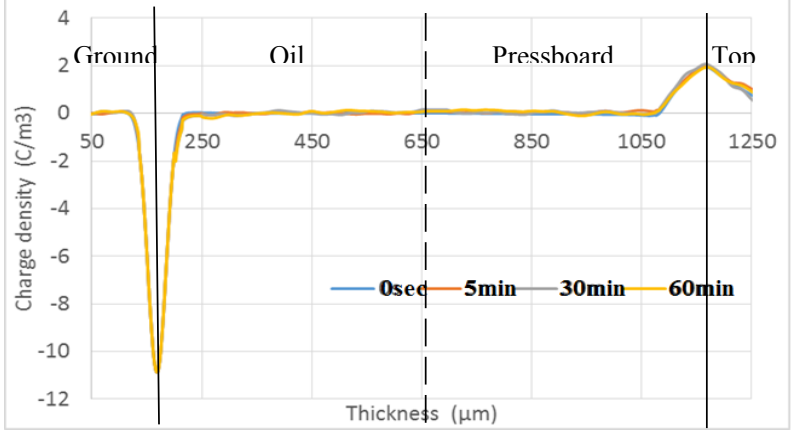

Fig. 8. Volts-on results of space charge in fresh oil combined with impregnated pressboard insulation system under $9.6 \mathrm{kV} / \mathrm{mm} \mathrm{AC}$ field at $81^{\circ}$.

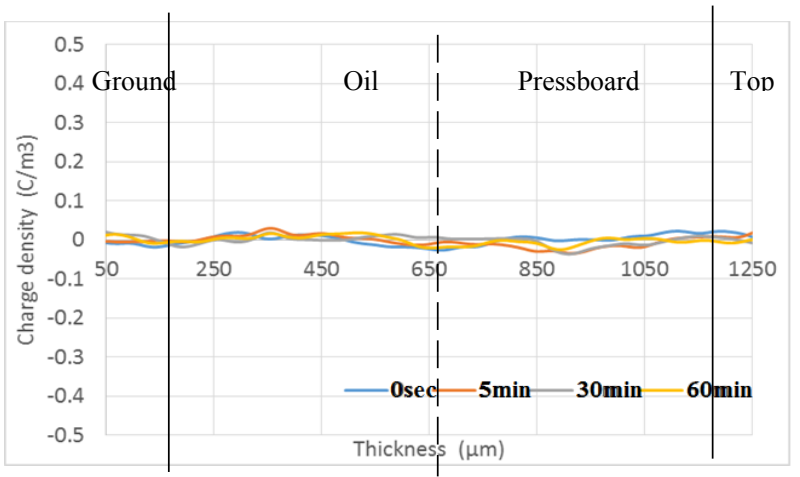

Fig. 9. Volts-off results of space charge in fresh oil combined with impregnated pressboard insulation system under $9.6 \mathrm{kV} / \mathrm{mm}$ AC field

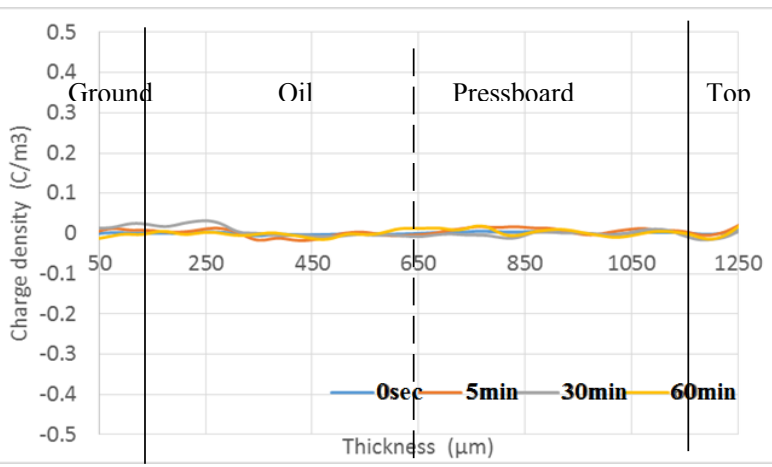

Fig. 10. Volts-off results of space charge in aged oil combined with impregnated pressboard insulation system under $9.6 \mathrm{kV} / \mathrm{mm}$ AC field.

TABLE II. SUMMARY OF THE TOTAL CHARGE AMOUNT AT 1 HOUR (nC)

\begin{tabular}{|c|c|c|c|}
\hline $\begin{array}{c}\text { Fresh oil } \\
\text { pressboard }\end{array}$ & $\begin{array}{c}\text { Aged oil } \\
\text { pressboard }\end{array}$ & $\begin{array}{c}\text { Fresh oil gap+ } \\
\text { pressboard }\end{array}$ & $\begin{array}{c}\text { Aged oil gap+ } \\
\text { pressboard }\end{array}$ \\
\hline 1.2 & 0.7 & $<0.1$ & $<0.1$ \\
\hline
\end{tabular}

\section{CONLUSIONS}

In this paper, the space charge characteristics in oil pressboard insulation system under AC stress have been investigated. By comparing the space charge behaviour in the four different dielectrics which are regarded as dielectrics with different charge motilities, the results suggest that 1) the amount of the space charge accumulated in the single layer pressboard is generally very small; 2) the space charge behaviour in oil/pressboard insulation system is related with the charge mobility in the dielectric materials, i.e. when the charge mobility is small in the single layer of the fresh oil impregnated pressboard, the accumulated charges (mainly negative charges) distribute in the narrow vicinity of the pressboard/ground electrode interface; when the charge mobility is higher in the single layer of the aged oil impregnated pressboard, the positive and negative charges could distribute broadly within the pressboard bulk; when the oil gap is applied, in which both positive charges and negative charges are believed to drift much faster than in the pressboard, hence the injected charges may keep drifting within the oil gap rather than being trapped by the oil/pressboard interface.

\section{ACKNOWLEDGMENT}

The authors are grateful to the Chongqing Electric Power Co for their financial support.

\section{REFERENCES}

[1] M. Jeroense and P. Morshuis, "Space charge measurements on impregnated paper: a review of the pea method and a discussion of results", IEEE Electrical Insulation Magazine, vol. 13(3), pp. 26-35, May 1997.

[2] R. Liu and G. Wahlstrom, "Measurements of the DC electric field in liquid impregnated pressboard using the pressure wave propagation technique", Conference Record of the 1994 JEEE International Symposium on Electrical Insulation, Pittsburgh, PA USA, June 5-8, 1994.

[3] M. Hao, Y. Zhou, G. Chen, G. Wilson, and P. Jarman, "Space charge behavior in thick oil-impregnated pressboard under HVDC stresses," Dielectrics and Electrical Insulation, IEEE Transactions on, vol. 22, pp. 72-80, 2015.

[4] J. Zhao, Z. Xu, G. Chen, and P. L. Lewin, "Numeric description of space charge in polyethylene under ac electric fields," Journal of Applied Physics, vol. 108, p. 124107, 2010

[5] C. Laurent, G. Teyssedre, and G. C. Montanari, "Time-resolved space charge and electroluminescence measurements in polyethylene under ac stress," Dielectrics and Electrical Insulation, IEEE Transactions on, vol. 11, pp. 554-560, 2004.

[6] A. See, J. C. Fothergill, L. A. Dissado, and J. M. Alison, "Measurement of space-charge distributions in solid insulators under rapidly varying voltage using the high-voltage, high-speed pulsed electro-acoustic (PEA) apparatus," Measurement Science and Technology, vol. 12, p. 1227, 2001.

[7] G. Chen, M. Fu, X. Z. Liu, and L. S. Zhong, "Ac aging and space-charge characteristics in low-density polyethylene polymeric insulation," Journal of applied physics, vol. 97, p. 083713, 2005.

[8] S. Bamji, M. A. Dakka, and A. Bulinski, "Phase-resolved pulsed electroacoustic technique to detect space charge in solid dielectrics subjected to AC voltage," Dielectrics and Electrical Insulation, IEEE Transactions on, vol. 14, pp. 77-82, 2007.6

[9] G. Chen, S. T. Li, and L. S. Zhong, "Space charge in polymeric insulation under ac electric fields-A schematic model," Electrical Insulation and Dielectric Phenomena (CEIDP), 2013 IEEE Conference on, pp. 663-666, Shenzhen, 2013.

[10] H. Jian, G. Chen, W. Gaolin, F. Jin, W. Qian, Y. Qiang and P. Huang, "Space charge characteristics of oil impregnated insulation paper under the power frequency voltage," Electrical Insulation and Dielectric Phenomena (CEIDP), 2013 IEEE Conference on, pp. 1314-1317, Shenzhen, 2013.

[11] M. Hao, Y. Zhou, G. Chen, G. Wilson, and P. Jarman, "Space charge behaviour in oil and impregnated pressboard combined insulation system," Dielectric Liquids (ICDL), 2014 IEEE 18th International Conference on, pp. 1-4, Bled, 2014. 